\title{
Distribution of the transposable element mariner in anopheline mosquitoes
}

\author{
MALLIKA IMWONG $\dagger$, ROSIE GAIL SHARPE $\dagger+$, PATTAMAPORN KITTAYAPONG $\dagger$ \\ \& VISUT BAIMAI†* \\ $\dagger$ Department of Biology, Faculty of Science, Mahidol University, Rama VI Road, Bangkok 10400, Thailand \\ and $\ddagger$ School of Biology, University of Leeds, Leeds LS2 9JT, UK
}

\begin{abstract}
We have surveyed the distribution of the transposable element mariner using PCR in 23 species of Anopheles mosquitoes, including all of the most important vectors of malaria in South-east Asia. Sequencing of the nine positive species revealed elements from the irritans, mauritiana and mellifera subfamilies. These are the first data showing the presence of three subfamilies of mariners in anophelines. The elements we encountered are likely to be inactive, based on the presence of multiple stop codons and/or frameshifts.
\end{abstract}

Keywords: horizontal transfer, mariner, Thailand, transgenic mosquitoes, transposon.

\section{Introduction}

Transposable elements (TEs) are a class of dispersed, repetitive DNA sequences, named because of their ability to change chromosomal position, that are a ubiquitous feature of eukaryote genomes (Berg \& Howe, 1989).

It has been suggested that the transmission of insectborne diseases may be interrupted by replacing insect vector populations with genetically engineered individuals that are unable to transmit disease (Curtis, 1994). Transposable elements may aid this proposal in three ways. The ability of active elements to be inherited by more than the Mendelian 50\% of offspring may be used to drive disease refractoriness genes into natural vector populations. Active elements may be used in the laboratory to transform the germline, as with $P$ elements (Rubin \& Spradling, 1982) and mariner in Drosophila (Lidholm et al., 1993; Lohe \& Hartl, 1996) and Aedes mosquitoes (Coates et al., 1998). Inactive elements, whose insertion sites remain sufficiently polymorphic between different laboratory strains or natural insect populations, may be used for genetic mapping and the analysis of insect population structure.

Active elements may cause deleterious mutations upon transposition, and thus a conflict exists between TEs and the rest of the nuclear genome. Mechanisms that inactivate or eliminate TEs will be selected (Warren \& Crampton, 1994), and an 'arms race' is expected to ensue. Such mechanisms are expected to suppress movement of all members of the same TE family

*Correspondence. E-mail: scvbm@mahidol.ac.th
(Kidwell, 1992). As a result, a particular TE may not be able to transform insects that already possess that TE family (Warren \& Crampton, 1994). It is therefore essential to know the native complement of TEs in natural populations of insect vectors before transformation procedures are attempted.

We have studied the distribution and evolution of the mariner TE in 23 species of Anopheles (Diptera: Culicidae) including all of the most important vectors of malaria in South-east Asia. The African malarial mosquito, An. gambiae sensu stricto is known to possess at least 100 copies of mariner in all strains examined (Robertson \& Lampe, 1995; Mukabayire \& Besansky, 1996) but data have not been reported for any other species of malarial vector.

The mariner family of TEs consists of sequences of approximately $1.3 \mathrm{~kb}$, with a single open reading frame and inverted terminal repeats of $28 \mathrm{bp}$, which are features characteristic of the DNA-mediated class of transposable elements (Hartl, 1989). The first mariner elements to be discovered, including the autonomous element Mosl, were isolated from Drosophila mauritiana (Jacobson et al., 1986). The vast majority of elements discovered so far contain multiple mutations (Maruyama \& Hartl 1991a,b; Robertson \& MacLeod, 1993; Robertson, 1993) and can therefore be considered to be pseudogenes. At least some nonautonomous elements are probably capable of transposition by means of trans complementation by autonomous elements; however, this has not been demonstrated directly.

Mariner elements have a wide phylogenetic distribution. They have been detected in a variety of arthropods 
as well as, for example, nematodes, hydras, flatworms and humans (Robertson et al., 1997). In a PCR survey of 404 arthropod species, 63 were found to contain mariner (Robertson \& MacLeod, 1993). The elements can be classified into at least five major subfamilies, which are $40-56 \%$ identical at the nucleotide level, and 16 minor subfamilies (Robertson et al., 1997).

\section{Materials and methods}

\section{Mosquito specimens}

Adult female mosquitoes were collected from Thailand between November 1994 and November 1997, using mosquito landing collection techniques. Species were identified using the morphological keys of Harrison \& Scanlon (1975), Peyton \& Scanlon (1966) and Rattanarithikul \& Green (1986). Members of the An. dirus complex were identified to species level by dot blot hybridization, using modifications to the methods of Panyim et al. (1988) and Audtho et al. (1995), described below.

Genomic DNA was prepared using the crude STE method of Robertson (1993). Individual insects were ground in $100 \mu \mathrm{l}$ of STE $(50 \mathrm{~mm} \mathrm{NaCl}, 10 \mathrm{~mm}$ Tris $\mathrm{pH} 8.0,1 \mathrm{~mm}$ EDTA), heated to $95^{\circ} \mathrm{C}$ for $10 \mathrm{~min}$ and spun at 13000 r.p.m. for $3 \mathrm{~min}$. The supernatant was removed to a fresh tube and stored at $-20^{\circ} \mathrm{C}$. Nylon membranes (GeneScreenPlus, Dupont, Wilmington, DL) were soaked in distilled water then in $10 \times \mathrm{SSC}$ solution ( $1.5 \mathrm{M} \mathrm{NaCl}, 0.15 \mathrm{M}$ sodium citrate) for $15 \mathrm{~min}$. The membrane was placed on a stack of 3 MM Whatman filter paper and spotted with genomic DNA, which was denatured by soaking twice in $0.5 \mathrm{~N} \mathrm{NaOH}$ for $5 \mathrm{~min}$, neutralized by soaking twice in $0.5 \mathrm{M}$ Tris- $\mathrm{HCl} \mathrm{pH} 7.4 /$ $1.5 \mathrm{M} \mathrm{NaCl}$ for $5 \mathrm{~min}$, then blotted onto $3 \mathrm{MM}$ Whatman filter paper. Membranes were incubated at $42^{\circ} \mathrm{C}$ for 30 min in hybridization solution $(50 \%$ formamide, $5 \times$ SSC, $5 \times$ Denhardt solution $(1 \%$ Ficoll $400,1 \%$ polyvinylpyrrolidone, $0.5 \%$ bovine serum albumin, $50 \mathrm{~mm}$ EDTA, $200 \mathrm{~mm}$ Tris $\mathrm{HCl} \mathrm{pH} 7.5$ ), $20 \mathrm{~mm}$ Tris $\mathrm{HCl}$ $\mathrm{pH} 8.0,100 \mu \mathrm{g} / \mathrm{ml}$ salmon sperm DNA, 2\% (SDS) and hybridized to digoxigenin-labelled species-specific probes. The probes were denatured by heating to $100^{\circ} \mathrm{C}$ for $10 \mathrm{~min}$ then snap-cooled on ice. $100-150 \mathrm{ng} \mathrm{mL}^{-1}$ of probe was added to the membrane and allowed to hybridize at $42^{\circ} \mathrm{C}$ for $18-24 \mathrm{~h}$ with gentle shaking. The membrane was washed twice with $3 \times \mathrm{SSC}$ for $15 \mathrm{~min}$ at room temperature, washed twice with $0.1 \times \mathrm{SSC} / 0.1 \%$ SDS for $30 \mathrm{~min}$ at $65^{\circ} \mathrm{C}$ and blotted onto Whatman 3 мм filter paper. Probes were detected by soaking the

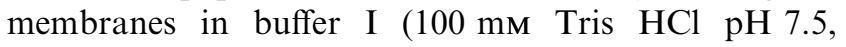
$150 \mathrm{~mm} \mathrm{NaCl}$ ) for $1 \mathrm{~min}$ at room temperature, incubating with blocking solution (Boehringer Mannheim,
Mannheim, Germany), washing in buffer I and incubating with $150 \mathrm{mU} / \mathrm{ml}$ antidig-conjugate (Boehringer Mannheim, Mannheim, Germany) at room temperature for $30 \mathrm{~min}$. The membrane was then washed twice with buffer I for $15 \mathrm{~min}$, further equilibrated with buffer III $(100 \mathrm{~mm}$ Tris $\mathrm{HCl}$ pH 8.5, $100 \mathrm{~mm} \mathrm{NaCl}, 50 \mathrm{~mm}$ $\mathrm{MgCl}_{2}$ ) for 2 min and incubated with substrate solution (10 $\mathrm{ml}$ buffer III, $45 \mu \mathrm{l}$ nitroblue tetrazolium chloride, $35 \mu$ 5-bromo-4-chloro-3-indolylphosphate) in the dark until colour developed. Development was halted by washing in distilled water for $10 \mathrm{~min}$.

\section{Polymerase chain reaction}

Genomic DNA was prepared using the STE method described above. Approximately $490 \mathrm{bp}$ regions of mariner elements were amplified by the polymerase chain reaction (PCR) using the degenerate primers MAR 124F and MAR 276R (Robertson, 1993). These primers amplify the central half of the transposase gene, representing one-third of the element. Amplifications were performed in $20 \mu \mathrm{l}$ volumes overlaid with one drop of mineral oil on a Hybaid OmniGene thermocycler. Each PCR included 2-20 ng of genomic DNA, 5 nmoles dNTP, $20 \rho$ moles each primer, 50 nmoles $\mathrm{MgCl}_{2}$ and 0.25 units of DNA polymerase using manufacturer's buffer (Promega, Madison, WI). Cycling conditions were $95^{\circ} \mathrm{C} 1 \mathrm{~min}, 50^{\circ} \mathrm{C} 1 \mathrm{~min}$ and $75^{\circ} \mathrm{C} 1 \mathrm{~min}$ for 40 cycles followed by a final extension at $75^{\circ} \mathrm{C}$ for $5 \mathrm{~min}$. Genomic DNA from Drosophila simulans was included with every set of PCRs as a positive control. Products were electrophoresed through ethidium bromide-stained 1\% agarose gels in $0.5 \times \mathrm{TBE}$ and visualized under UV light.

\section{Sequencing}

PCR products were cleaned using spin columns (Promega Wizard PCR Preps, Promega, Madison, WI) and cloned into a pGEM-T vector (Promega, Madison, WI). Plasmids were extracted (Wizard Minipreps, Promega) and sequenced in both directions using primers T7 and SP6 (AmpliTaq DNA polymerase, FS, Applied Biosystems on an automated sequencer, ABI 377). Two clones were sequenced from each individual, except for An. vagus, where only one individual was sequenced.

\section{Sequence analysis}

Sequences of mariner obtained here were compared with those of other invertebrates of the same mariner subfamilies (Robertson \& MacLeod, 1993; Robertson, 1993) and the active Mosl sequence (Jacobson et al., 1986). Nucleotide sequences were translated into their presumed amino acid sequences by assuming a number 
of frameshifts. Amino acid sequence and length differences were used to identify sequences to subfamily level, according to the diagnoses given in Robertson \& MacLeod (1993).

Amino acid sequences were aligned using PILEUP (Genetics Computer Group, 1994) from the GCG suite of programs (Program Manual for the Wisconsin Package 1994). Phylogenetic trees were inferred by PAM 001 and neighbor-joining using programs SEQBOOT, PROTDIST, NEIGHBOR and CONSENSE from PHYLIP version 3.5c (Felsenstein, 1993) and maximum parsimony analysis using a heuristic search and treating gaps and frameshifts as missing characters using PAUP version 3.1 (Swofford, 1991). One hundred bootstrap replications were carried out. Trees were rooted using the Bombyx mori Bmmarl sequence, which represents a basal lineage of the mariner family (Robertson \& Asplund, 1996).

\section{Results}

Table 1 shows which species of Anopheles were tested for the presence of mariner PCR products, as well as the Subgenus, Series and Group or Complex of the species. Positive species were from the An. maculatus and An. dirus complexes, as well as An. vagus and An. annularis. Both of these complexes contain the principal malaria vectors in Thailand and elsewhere in South-east Asia. However, the malaria vector An. minimus s.l. appears not to possess mariner that can be amplified by the primers used here. All sequences obtained have been submitted to GenBank (accession number AF294472-AF294488). Note that An. sawadwongporni was found to have representatives from two subfamilies. We do not suppose that the mariner elements we have found represent all of the elements in these species; if more clones were to be sequenced, we would expect to encounter more sequence variation in many, if not all, of the species.

None of the mariners we encountered are likely to be autonomous. They all contain multiple stop codons and/ or frameshifts. Sequences from An. vagus are severely truncated. The closest resemblances to the active Mos 1 sequence are in An. dirus D and An. sawadwongporni, in the mauritiana subfamily, although these are $51.7 \%$ and $82.3 \%$ divergent at the DNA level, respectively (Kimura

Table 1 Presence and absence of mariner PCR products in species of Anopheles. Absence implies that mariner was not detected in any of the specimens; presence implies that it was detected in at least some specimens. $N=$ number of individual tested. Mosquito classification from Harbach (1994)

\begin{tabular}{|c|c|c|c|c|c|c|c|}
\hline $\begin{array}{l}\text { Species of } \\
\text { Anopheles }\end{array}$ & Subgenus & Series & $\begin{array}{l}\text { Group (G) or } \\
\text { Complex (C) }\end{array}$ & $N$ & $\begin{array}{l}\text { Presence }(+) \\
\text { or absence }(-) \\
\text { of mariner }\end{array}$ & $\begin{array}{l}\text { No. clones } \\
\text { sequenced }\end{array}$ & $\begin{array}{l}\text { Subfamily } \\
\text { of mariner }\end{array}$ \\
\hline barbirsotris & Anopheles & Nyssorhynchus & Barbirostris $\mathrm{G}$ & 12 & - & & \\
\hline hyrcanus s.l. & Anopheles & Nyssorhynchus & Hyrcanus G & 10 & - & & \\
\hline peditaeniatus & Anopheles & Nyssorhynchus & Hyrcanus G & 9 & - & & \\
\hline aconitus & Cellia & Myzomyia & Minimus $\mathrm{G}$ & 11 & - & & \\
\hline culicifacies s.l. & Cellia & Myzomyia & Culicifacies $\mathrm{C}$ & 3 & - & & \\
\hline minimus s.l. & Cellia & Myzomyia & Minimus G & 40 & - & & \\
\hline varuna & Cellia & Myzomyia & Minimus $\mathrm{G}$ & 1 & - & & \\
\hline dirus $A$ & Cellia & Neomyzomyia & Leucosphyrus G; Dirus C & 9 & + & 2 & irritans \\
\hline dirus $C$ & Cellia & Neomyzomyia & Leucosphyrus G; Dirus C & 21 & + & 2 & irritans \\
\hline dirus $D$ & Cellia & Neomyzomyia & Leucosphyrus G; Dirus C & 4 & + & 2 & mauritiana \\
\hline kochi & Cellia & Neomyzomyia & - & 13 & - & & \\
\hline tessellatus & Cellia & Neomyzomyia & - & 17 & - & & \\
\hline annularis & Cellia & Neocellia & Annularis G & 8 & + & 2 & irritans \\
\hline dravidicus & Cellia & Neocellia & Maculatus C & 1 & + & 2 & irritans \\
\hline jamesii & Cellia & Neocellia & - & 10 & - & & \\
\hline maculatus s.s & Cellia & Neocellia & Maculatus C & 40 & + & 2 & irritans \\
\hline nivipes s.1. & Cellia & Neocellia & Annularis G; Nivipes C & 12 & - & & \\
\hline pseudowillmori & Cellia & Neocellia & Maculatus C & 1 & - & & \\
\hline sawadwongporni & Cellia & Neocellia & Maculatus C & 10 & + & 2 & $\begin{array}{l}\text { irritans }+ \\
\text { mauritiana }\end{array}$ \\
\hline splendidus & Cellia & Neocellia & - & 23 & - & & \\
\hline willmori & Cellia & Neocellia & Maculatus C & 11 & + & 2 & irritans \\
\hline subpictus & Cellia & Pyretophorus & Subpictus C & 11 & - & & \\
\hline vagus & Cellia & Pyretophorus & - & 8 & + & 1 & mellifera \\
\hline
\end{tabular}

(C) The Genetical Society of Great Britain, Heredity, 85, 271-276. 
2-parameter distance using a transition:transversion ratio of 1:2). As expected if the elements have not been active recently, nonsynonymous substitutions are more common than synonymous substitutions, even in the sequences that are most similar to active elements (An. dirus D, 82:26 and An. sawadwongporni, 86:40).

The neighbor-joining phylogram of the mariner sequences from species of Anopheles and other invertebrates is shown in Fig. 1. Maximum parsimony analysis supported all major branches. Bootstrap values within mariner subfamilies are not particularly high, as expected for highly degraded elements. The analysis does, however, clearly show that the elements encountered fall into three of the five known major subfamilies of mariner: mellifera, mauritiana and irritans.

Some of the relationships indicated are difficult to explain without involving horizontal transfer. For example, mariner sequences from the Dipteran An. dirus $\mathrm{C}$ and the Neuropteran green lacewing are very closely related $(96.7 \%$ DNA identity) and yet the orders are thought to have last shared a common ancestor approximately 265 Ma (Harland et al., 1990).

\section{Discussion}

\section{A note on species identification}

Anopheles willmori has not previously been recorded from low elevations, and we therefore identify it with some caution. Species distributions are not well known, and we consider it likely that this specimen does represent An. willmori. However, it is also possible that it belongs to another member of the An. maculatus complex, or to a previously undetected member of the complex. There has been a long-standing question about the conspecificity of the chromosomal forms B, $\mathrm{E}$ and $\mathrm{F}$ of An. maculatus, which all finally came to be regarded as one species (Green et al., 1992). It is possible that the An. willmori here equates to one of these forms.

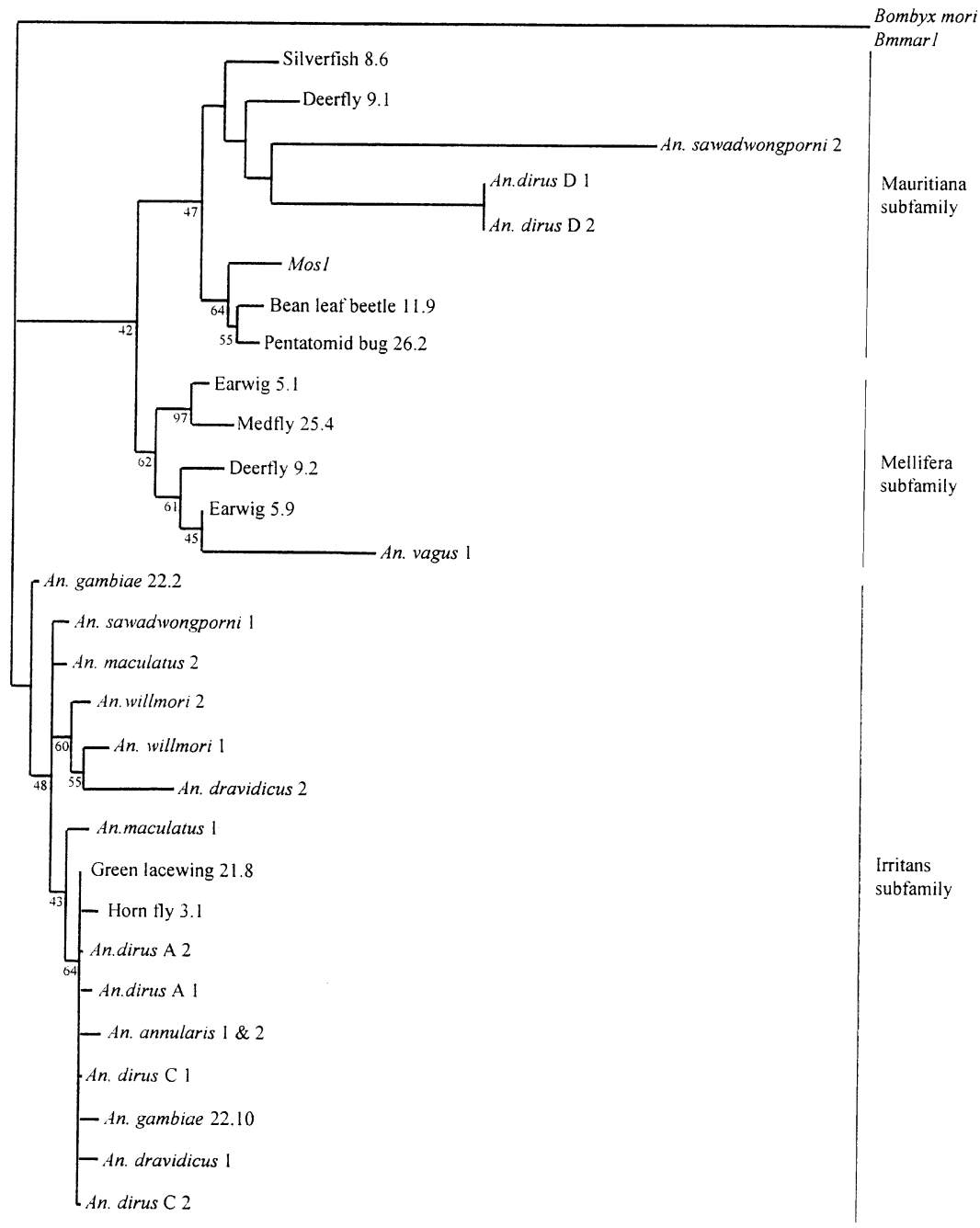

Fig. 1 Neighbor-joining phylogram reconstructed using an amino acid alignment of mariner sequences. All sequences from Anopheles obtained herein; all other sequences are from the GenBank database. Bootstrap percentages greater than 40 are indicated below the branches.

(c) The Genetical Society of Great Britain, Heredity, 85, 271-276. 


\section{Distribution of mariner}

Our survey reveals that the transposable element mariner is common in South-east Asian Anopheles mosquitoes, including two of the three major malaria vector complexes: those of An. dirus and An. maculatus. The third major malaria vector, An. minimus s.l. does not appear to be infected, despite testing of 40 individuals. However, we did not identify this complex to species level therefore the possibility remains that some members do carry mariner.

Anopheles mosquitoes contain a diversity of mariner elements. We detected elements from three subfamilies: irritans, mauritiana and mellifera, and despite sequencing a maximum of two clones per species, we detected mariners of two different subfamilies in the genome of An. sawadwongporni, a member of the Maculatus Complex. This implies that many more mariner elements are likely to be found in these genomes. None of the elements we sequenced are likely to be autonomous, although this does not, of course, preclude the presence of autonomous elements in the genomes of these mosquitoes.

\section{Acknowledgements}

This work was supported by grants from the Thailand Research Fund (RTA/38/80008) and the UNDP/World Bank/WHO Special Programme for Research and Training in Tropical Disease (ID-940196). We thank Umnaj Chanama for carrying out the dot blot hybridizations, Porn Sawadwongporn for help with the morphological identifications and Hugh Robertson for sending us his mariner alignments. Automated sequencing was carried out by the Bioservices Unit, Bangkok. We thank Kathy Baisley, Roger Butlin and Scott O'Neill for critically reading the manuscript.

\section{References}

AUDTHO, M., TASSANAKAJON, A., BOONSAENG, V., TPIANKIJAGUM, S. AND PANYIM, S. 1995. Simple nonradioactive DNA hybridization method for identification of sibling species of Anopheles dirus (Diptera: Culicidae) complex. J. Med. Entomol., 32, 107-111.

BERG, D. E. AND Howe, M. M. 1989. Mobile DNA. American Society for Microbiology, Washington, DC.

COATES, C. J., JASINSKIENE, N., MIYASHIRO, L. AND JAMES, A. A. 1998. Mariner transposition and transformation of the yellow fever mosquitoes, Aedes aegypti. Proc. Natl. Acad. Sci. U.S.A., 95, 3748-3751.

CURTIS, C. F. 1994. The case for malaria control by genetic manipulation of its vectors. Parasitol. Today, 10, 371-374.

FELSENSTEIN, J. 1993. PHYLIP (Phylogeny Inference Package), Version 3.5c. Department of Genetics, University of Washington, Seattle, WA.
GENETICS COMPUTER GROUP. 1994. Program manual for the Wisconsin Package, Version 8. 575 Science Drive, Madison, WI.

GREEN, C. A., RATTANARITHIKUl, R. AND CHAROENSUb, A. 1992. Population genetic confirmation of species status of the malaria vectors Anopheles willmori and An. pseudowillmori in Thailand and chromosome phylogeny of the Maculatus group of mosquitoes. Med. Vet. Ent., 6, 335-341.

HARBACH, R. E. 1994. Review of the internal classification of the genus Anopheles (Diptera: Culicidae): the foundation for comparative systematics and phylogenetic research. Bull. Ent. Res., 84, 331-342.

harland, W. B., ARMSTRONG, R. L., COX, A. V., CRAiG, L. E., Smith, A. G. AND SMITH, D. G. 1990. A Geologic Time Scale. Cambridge University Press, Cambridge.

HARRISON, B. A. AND SCANLON, J. E. 1975. Medical Entomology Studies - II. The subgenus Anopheles in Thailand (Diptera: Culicidae). Contr. Am. Entom. Inst., 12, 1-307.

HARTL, D. L. 1989. Transposable element mariner in Drosophila species. In: Berg, D. E. and Howe, M. M. (eds) Mobile $D N A$, pp. 531-536. American Society for Microbiology, Washington, DC.

JACOBSON, J. W., MEDHORA, M. M. AND HARTL, D. L. 1986. Molecular structure of somatically unstable transposable element in Drosophila. Proc. Natl. Acad. Sci. U.S.A., 83, 8684-8688.

KIDWELl, M. G. 1992. Horizontal transfer. Curr. Opin. Gen. Dev., 2, 868-873.

LIDHOLM, D. A., LOHE, A. R. AND HARTL, D. L. 1993. The transposable element mariner mediates germline transformation in Drosophila melanogaster. Genetics, 134, 859-868.

LOHE, A. R. AND HARTL, D. L. 1996. Germline transformation of Drosophila virilis with the transposable element mariner. Genetics, 143, 365-374.

MARUYAMA, K. AND HARTL, D. L. 1991a. Evolution of transposable element mariner in Drosophila species. Genetics, 128, 319-329.

MARUYAMA, K. AND HARTL, D. L. 1991b. Interspecific transfer of the transposable element mariner between Drosophila and Zaprionus. J. Mol. Evol., 33, 514-524.

MUKABAYIRE, O. AND BESANSKY, N. J. 1996. Distribution of T1, $\mathrm{Q}$, Pegasus and mariner transposable elements on the polytene chromosome of PEST, a standard strain of Anopheles gambiae. Chromosoma, 104, 585-595.

PANYIM, S., YASOTHORNSRIKUL, S., TUNGPRADUBKUL, S., BAIMAI, V., ROSENBERG, R., ANDRE, R. G. ET AL. 1988. Identification of isomorphic malaria vectors using DNA probe. Am. J. Trop. Med. Hyg., 38, 47-49.

PEYTON, E. L. AND SCANLON, J. E. 1966. Illustrated key to the female Anopheles Mosquitoes of Thailand. US Army Medical Component, Southeast Asia Treaty Organisation, Bangkok, Thailand.

RATTANARITHIKUL, R. AND GREEN, C. A. 1986. Formal recognition of the species of the Anopheles maculatus group (Diptera, Culicidae) occurring in Thailand, including the descriptions of two new species and a preliminary key to females. Mosq. Syst., 18, 246-277. 
ROBERTSON, H. M. 1993. The mariner transposable element is widespread in insects. Nature, 362, 241-245.

ROBERTSON, H. M., SOTO-ADAMES, E. N., WALDEN, K. K. O. AND LAMPE, D. J. 1997. The mariner transposons of animals: horizontally jumping genes. In: Syvanen, M. (ed.) Horizontal Gene Transfer: Implications and Consequences, pp. 268-284. Chapman \& Hall, London.

ROBERTSON, H. M. AND ASPLUND, M. L. 1996. Bmmarl: a basal lineage of the mariner family of transposable elements in the silkworm moth, Bombyx mori. Insect Biochem. Mol. Biol., 26, 945-954.

ROBERTSON, H. M. AND LAMPE, D. J. 1995. Recent horizontal transfer of a mariner transposable element among and between Diptera and Neuroptera. Mol. Biol. Evol., 12, 850-862.
ROBERTSON, H. M. AND MACLEOD, E. G. 1993. Five major subfamilies of mariner transposable elements in insects, including the Mediterranean fruit fly, and related arthropods. Ins. Mol. Biol., 2, 125-139.

RUBIN, G. M. AND SPRADLING, A. C. 1982. Genetic transformation of Drosophila with transposable element vectors. Science, 218, 348-353.

SWOFFORD, D. L. 1991. PAUP: Phylogenetic Analysis Using Parsimony, Version 3.1. Illinois Natural History Survey, Champaign, IL.

WARREN, A. M. AND CRAMPTON, J. M. 1994. Mariner: Its prospects as a DNA vector for the genetic manipulation of medically important insects. Parasitol. Today, 10, $58-63$. 